\title{
Developing the Model of Psychological Well-Being in Elderly Based on Life Expectancy Through Mediation of Death Anxiety
}

Nasrin Bakhshi

* PhD Student in Health Psychology, Islamic Azad University, UAE Branch. Dubai, United Arab Emirates (corresponding author): nasrinbakhshi7@gmail.com

Sarah Pashang

Assistant Professor of Psychology, Islamic Azad University, Karaj Branch. Iran.

Nematollah Jafari

Professor of Psychiatry, University of Poitiers, France

Shoreh Ghorban-Shiroudi

Associate Professor of Psychology, Islamic Azad University, Tonekabon Branch. Iran.

Received: 2020/01/31

Accepted: 2020/06/15

Doi: 10.29252/ijhehp.8.3.283

\section{ABSTRACT}

Background and Objective: The purpose of the present study was to developing the model of psychological well-being in elderly based on life expectancy through mediation of death anxiety.

Materials and Methods: The research method is correlational and structural modeling equation. The statistical population of this study included all the elderly hospitalized in the sanatorium and the elderly at home in Tehran in 2019. The sample included 400 elderly people selected by cluster sampling. In this way, among the elderly care centers and neighborhood house, 10 centers were selected randomly from districts 2, 3 and 5 in Tehran and then 40 elderly people were randomly selected from each center 400 elderly in total and the questionnaires were completed by them and in the presence of the researcher. Research instruments included Ryff Psychological Well-being Questionnaire (1989), Templer Death Anxiety Scale (1970) and Snyder Hope Scale (1991). The research data were analyzed by structural equation modeling and Sobel intermediate test.

Results: The results of the conceptual model test indicated that the fit indices of the research model were in good condition $(\mathrm{GFI}=0.98)$. Hope had a direct effect on psychological well-being $(p<0.05, \beta=0.47)$. The hypothesis regarding the indirect effect of hope on the psychological well-being of the elderly through death anxiety was also confirmed $(p<0.05, \beta=0.13)$.

Conclusion: The findings of the study indicated that the conceptual model of the research was appropriate. Therefore, in elderly care centers, it is necessary to pay attention to the antecedents of hope and death anxiety in order to increase the level of psychological well-being and Improving the health of the elderly. Keywords: Psychological Well-being, Life-Expectancy, Death Anxiety, Elderly Paper Type: Research Article.

Citation (Vancouver): Bakhshi N, Pashang S, Jafari N, Ghorban-Shiroudi SH. Developing the Model of Psychological Well-Being in Elderly Based on Life Expectancy Through Mediation of Death Anxiety. Iran J Health Educ Health Promot. Spring 2020;8(3):283-293. [Persian]x

- Citation (APA): Bakhshi N., Pashang S., Jafari N., Ghorban-Shiroudi SH. Developing the Model of Psychological Well-Being in Elderly Based on Life Expectancy Through Mediation of Death Anxiety. Iranian Journal of Health Education \& Health Promotion., 8(3), 283-293. [Persian] 


\section{ارائه مدل بهزيستى روانشناختى سالمندان بر اساس اميد به زندكى با ميانجيكرى اضطراب مركى}

\section{جكيده}

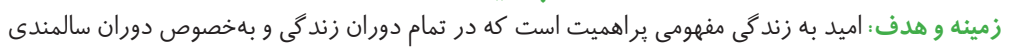

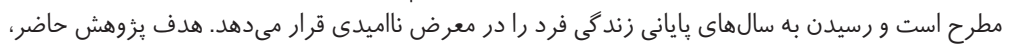

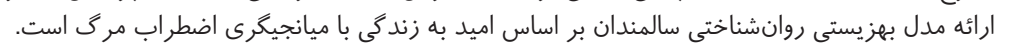

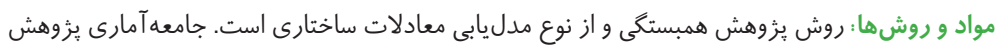

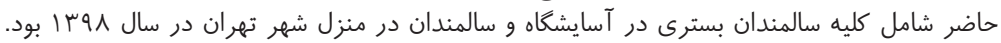

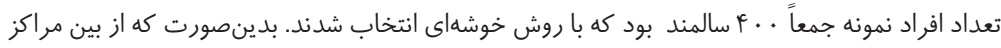

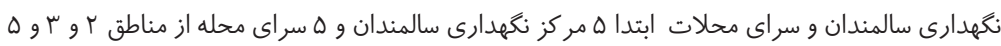

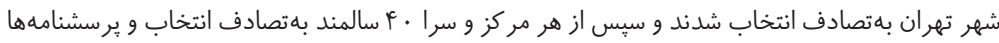

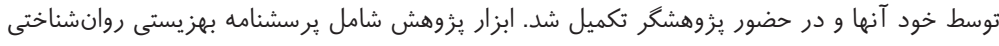

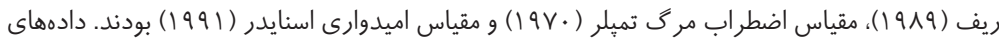

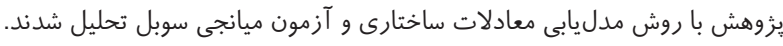

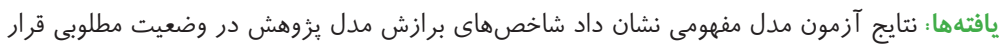

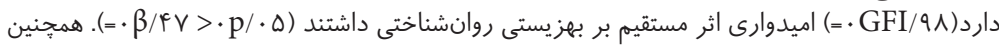

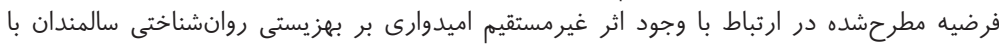

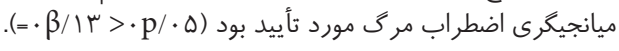

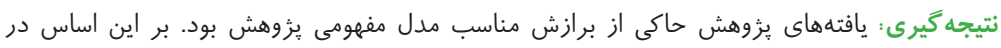

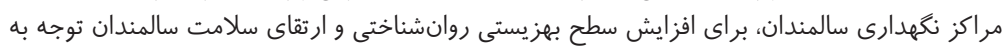

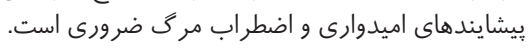

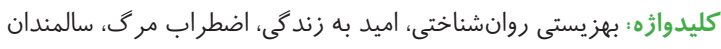

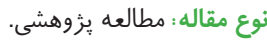

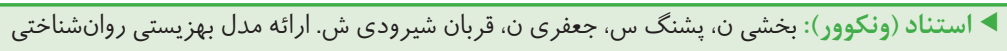

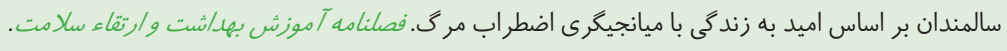

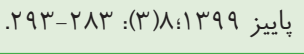

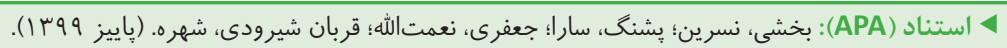

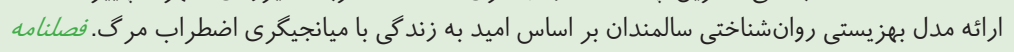

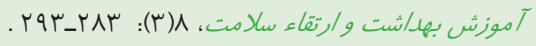

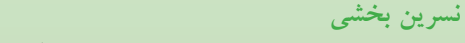

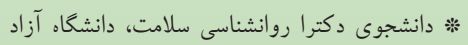

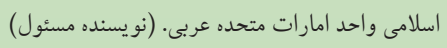
nasrinbakhshi7@gmail.com

سارا پشنگ استاديار روانشناسى، دانشكاه آزاد اسلامى واحد كرج

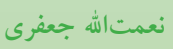
استاد روان يزشكى، دانشكاء يو آتيه فرانسه

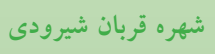
دانشيار روانشناسى، دانشكاه آزاد اسلامى واحد تنكابن

تاريخ د ريافت: | | | | | |

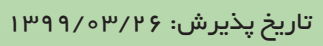


زندگى براى ساختن ويز گیىهاى مثبت است. در اين رويكرد، به

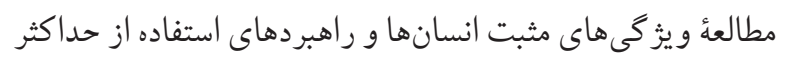

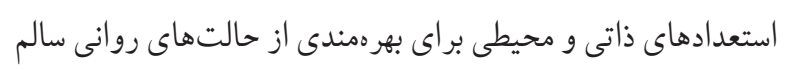

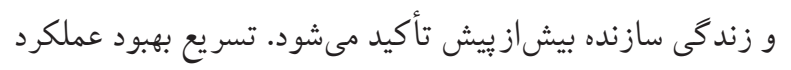
و اصلاحات اشتباهات كذشته در جهت ساختن خصوصيات مثبت است كه شامل بهزيستى، خرسندى و رضايت در كذشته و اميد و

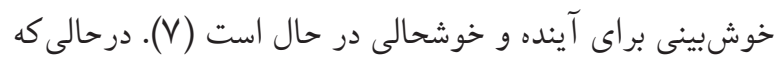

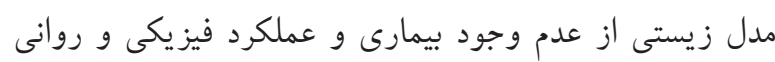

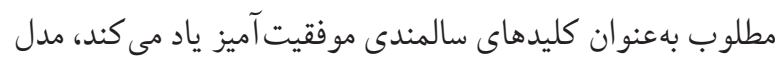
اجتماعى -روانى بر رضايت زندگى، مشاركت اجتماعى، عملكرد

و منابع روانى شامل رشد شخصى تأكيد دارد (^).

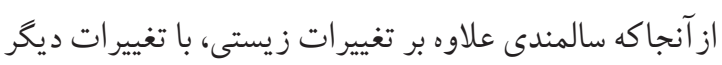
در زندگى مانند بازنشستخى، انتقال به محل سكونت مناسب شر ايط

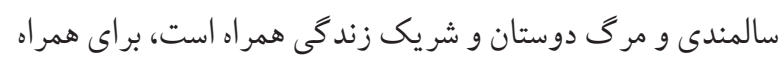

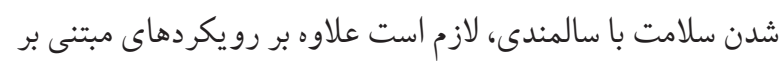

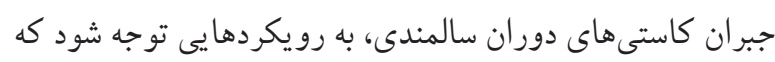

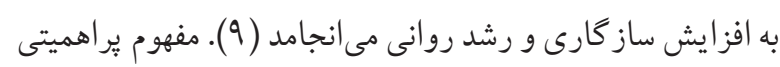
كه در تمام دوران زندگى و بهخصوص دوران سالمندى مطرح است،

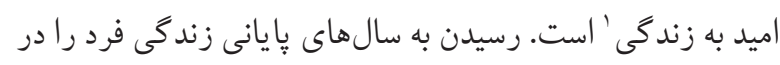

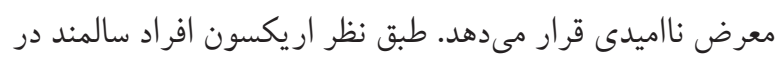
شرايط فقدان همسر، دوستان، سلامت جسمانى، هوشيارى، استقلال

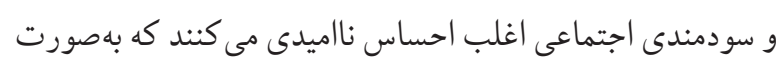

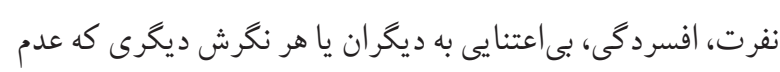

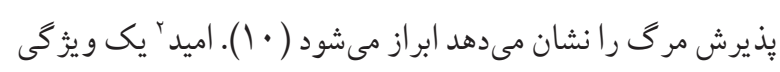

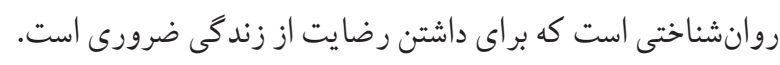

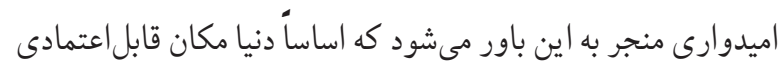

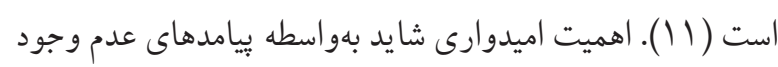

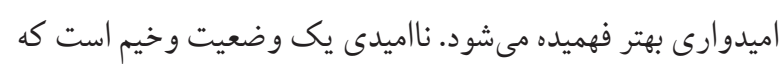

1. life Expectancy 2. hope
مقالمه

تركيب جمعيت جهان در حال تغيير بوده و بيشرفتهاى دانش

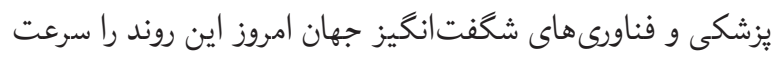

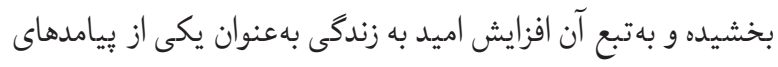

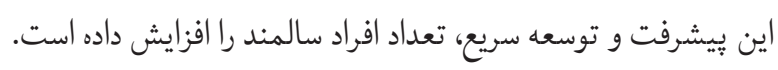

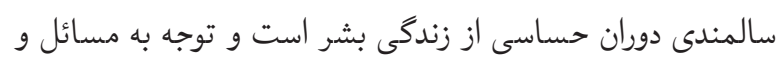

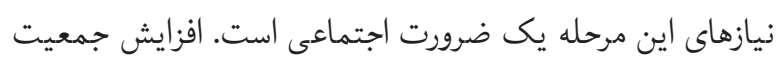

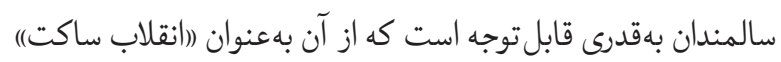
ياد شده است. بررسى شاخصهاى آمارى در ايران حاكى از رشد و شتاب سالمندى است، بهطورى كه يِيشبينى ميى شود در سال .

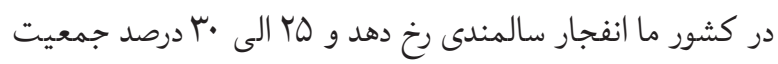

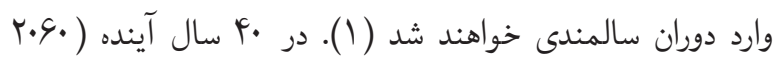

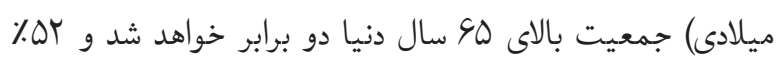

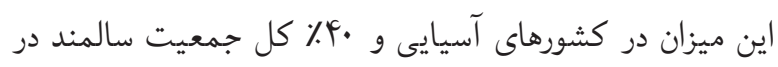

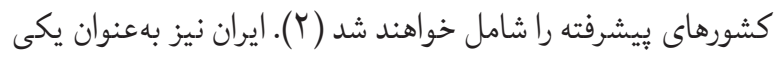

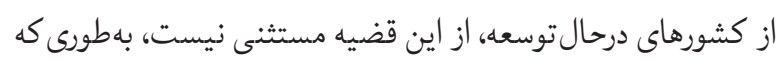
روند بير شدن در كشور از رشد جمعيت سالمندى حكايت دارد (ץ).

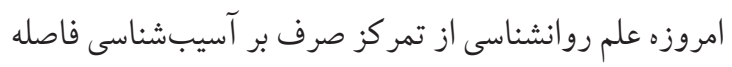
كرفته و رويكرد روانشناسى مثبت نكر نيز در سرلوحه كار بثزوهشكران

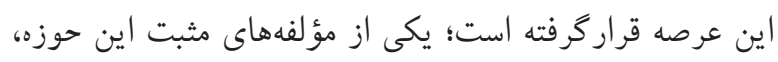

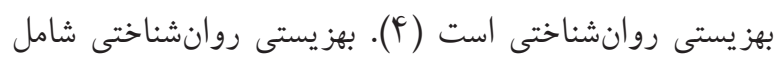

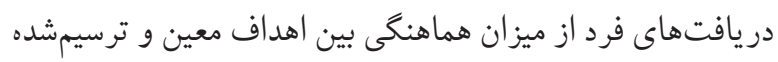

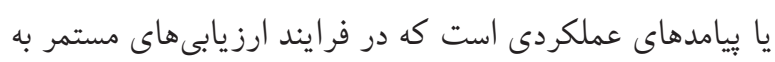

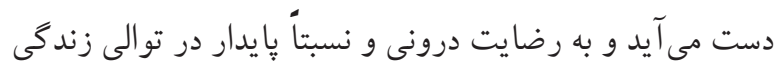

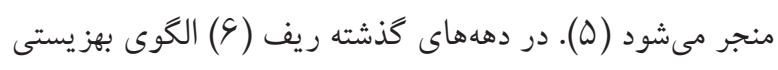

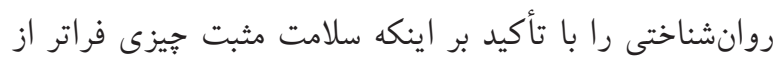

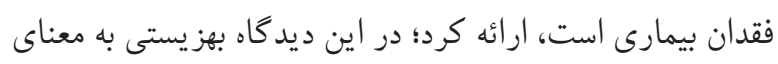

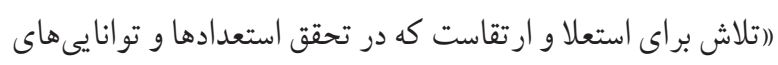
فرد متجلى مى شود.)) بهز يستى روانشناختى از روانشناسى مثبت إنقاست

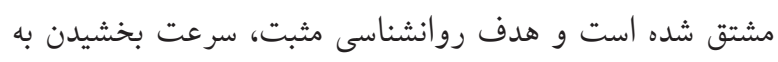

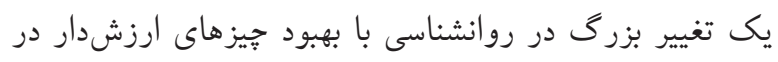


مى تو اند سلامت وجودى و مخصوصاً كار كرد سلامت روانى افر اد را تحت تأثير قرار دهد. اضطر اب و ترس از مرك در تمام فرهنگ ونها

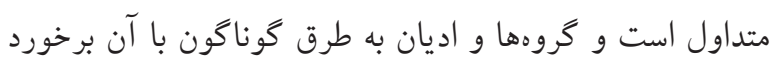

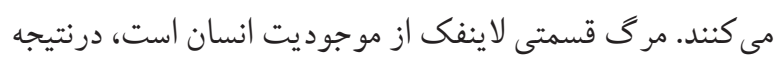

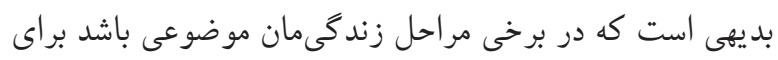

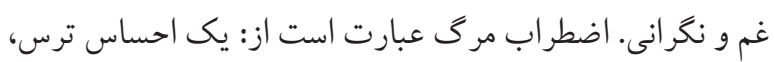
هراس يا نكرانى زمانى كه يك نفر به فرايند مردن، توقف آينده

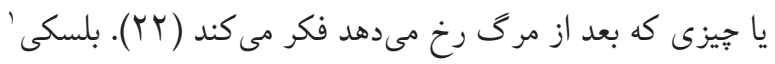

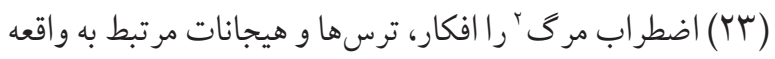

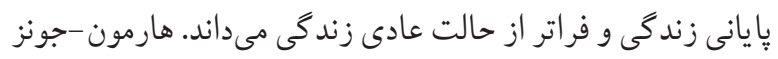

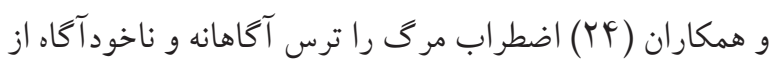
مرگ يا مردن مى دانند. اضطراب مرى مفهومى يبيجيده است كه

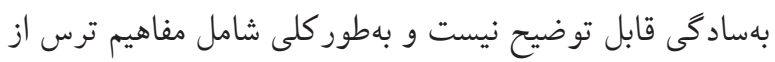

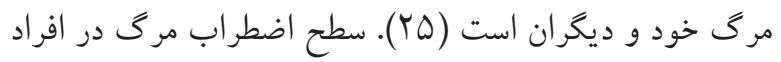

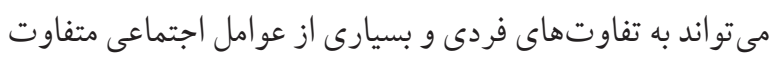

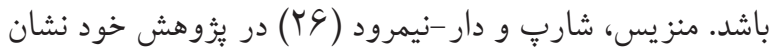

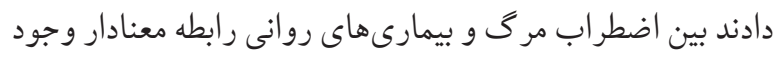
دارد. در همين راستا نتايج يخوهش ورعى و همكاران (YV) نشان

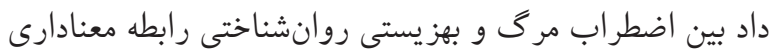

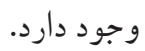
با توجه به مطالب بيانشده مىتوان كفت مشكلات روانى در

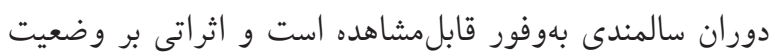

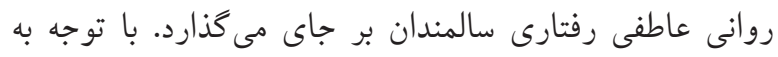
آسيب بذير بودن افراد سالمند اين قشر ازجمله كروههائي هستند

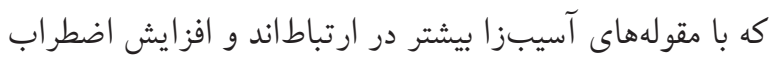

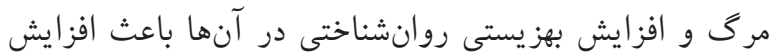
تو انايى ها و عملكردهاى مثبت ايشان مىشود. نظر به تعدد عوامل

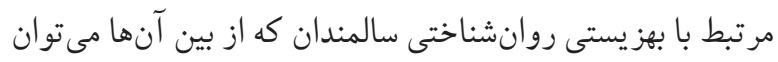

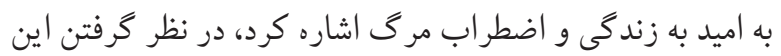
عوامل در مدلهاى مرتبط با بهزيستى روانشناختى سالمندان از ردي

1. Belskey

2. Anxiety Death
منجر به افزايش يأس، افسردگى و نهايتاً فقدان اشتياق به زندگى

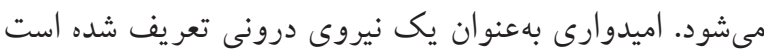

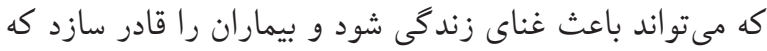
جشم اندازى فراتر از وضعيت كنونى و نابسامان درد و رنج خود راس راس

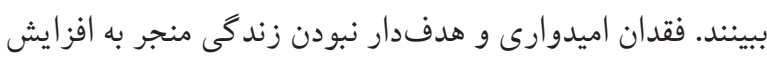
كيفيت آن و ايجاد باورهاى يأس آور مىشود ( ا I). جهت يابى آينده، انتظارات مثبت، هدفمندى، واقع گرايى، تنظيم اهداف و ارتباطات درونى از ويز گىهاى مهم اميدوارى هستند. اميدوارى دربردارنده

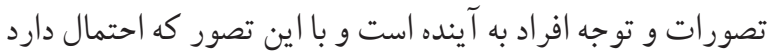

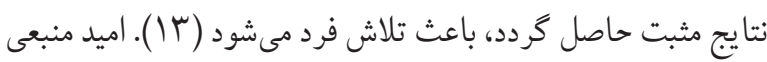

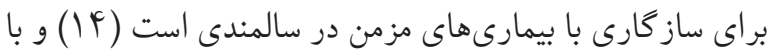
ارتقاى اميد به زندگى و سلامت جسمى و روانشناختى و فراهم آوردن زمينههاى استقلال، روابط سالم، بهخصوص روابط خانوادكى سلى

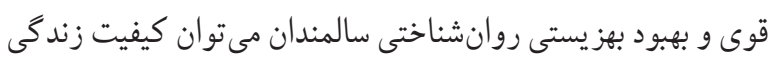

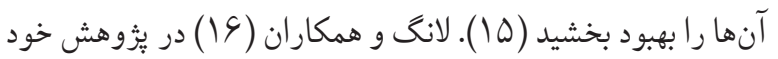

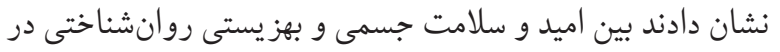

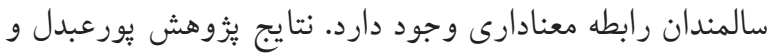
همكاران (11) نشان دادند كه بين بهز يستى روانشناختى و اميد به زندگى با كيفيت زندگى سالمندان رابطه مثبت معنادارى وجود دارد. همجنين نتايج يُّوهش كشاورز (1) نشان داد بين اميد به زندگى با بهز يستى روانشناختى رابطه مستقيم معنى دار وجود دارد. همجنين نتايج يُزوهش نظامدوست و همكاران (19 (1) نشان داد بين اميد و بهز يستى روانشناختى در سالمندان رابطه معنادار وجود دارد.

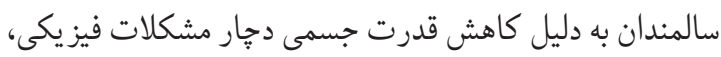
اجتماعى و اقتصادى بيشترى نسبت به ديخر گروههاى سنى مى شوند

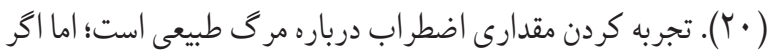

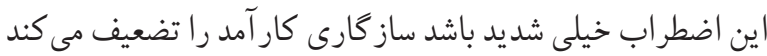

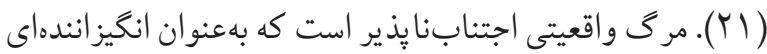
قوى تصور شده كه در پشت بسيارى از اظهارات و جستجوهاى فلسفى سالهاى زندگى قرار داردو به خاطر ماهيت يٍر ابهامش براى

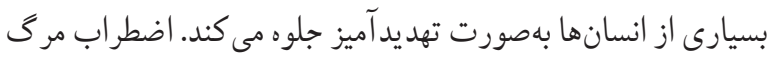




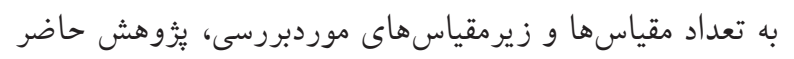

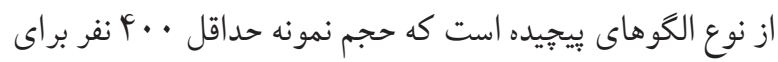
آن ييشنهاد شده است.

معيارهاى ورود به يثوهش آزمودنىها در هر دو گروه عبارت بودند از: حداقل داشتن · • سال سن، حداقل تحصيلات سيكل

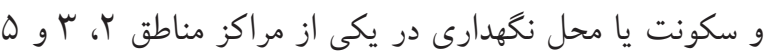
شهر تهران و تمايل به همكارى در يُّوهش. در اين يُوهش كليه

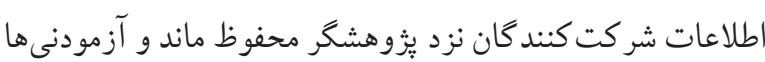
هيج اجبارى براى شر كت در يزوهش وجود نداشتند.

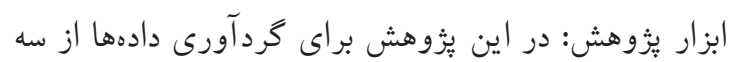

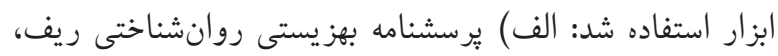
ب) يرسشنامه اميد اسنايدر و ج) مقياس اضطر اب مرى تميلر. الف) برسشنامه بهزيستى روانشناختى ريف: اين يرسشنامه توسط لبرس ريف (9) ساختهشده است. در اين مقياسها ياسخ به هر سؤال بر روى يك طيف ششدرجهاى (از كاملاً مخالف تا كاملاً موافق)

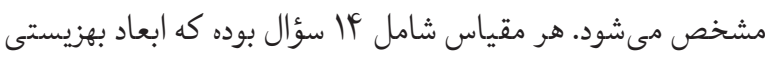

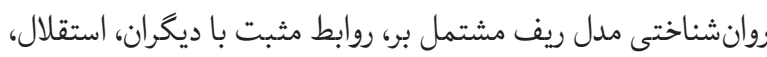

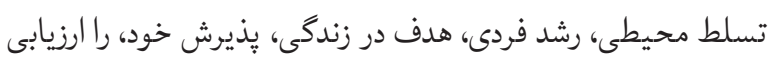

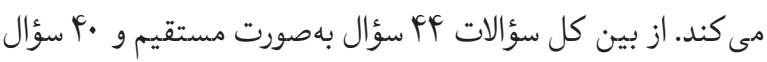
بهصورت معكوس نمره كذارى مىشود. آلفاى كرونباخ بهدست آمده

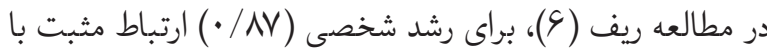

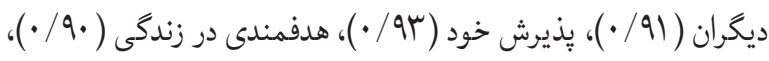

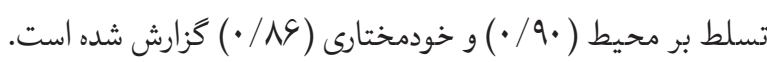

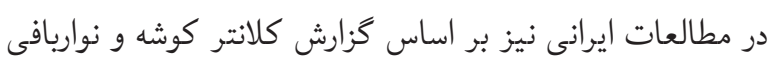

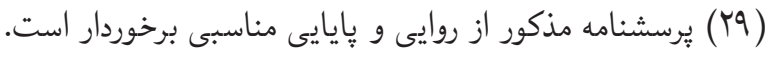
در اين تحقيق نيز ضريب آلفاى كرونباخ سץ/ • • بهدست آمده است. ب) بٕسشنامه اميد اسنايدر: اميدوارى در يزوهش حرئ حاضر بهوسيله

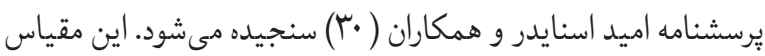

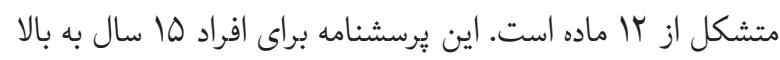

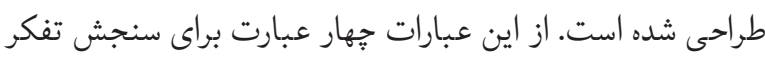

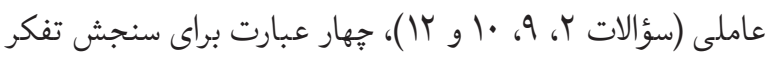

اهميت ويزهاى برخوردار است. اين امر در عين اهميت، كمتر

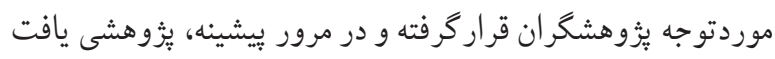

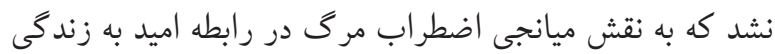

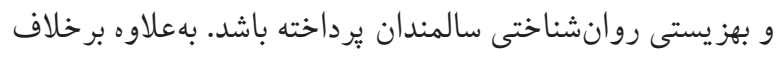

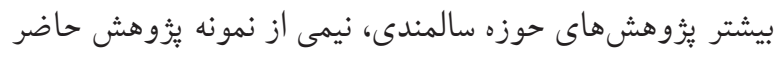

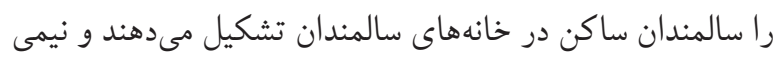
را سالمندان ساكن منزل تا نقش اين متغير تعديل شود. همجنين

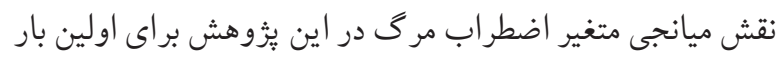
مطرح است. درمجموع يزوهش حاضر درصدد پِاسخكويى به اين

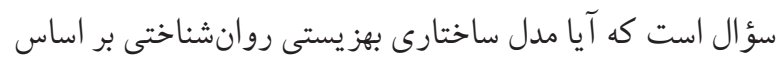

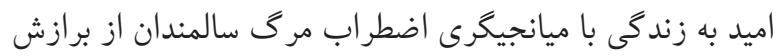

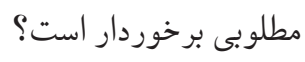
مو اد و روشها اين يثوهش با توجه به هدف آن از نوع تحقيقات كاربردى و ازلحاظ

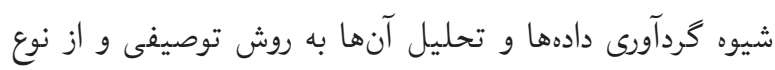
طرح هاى همبستخى و روش مدل يابى معادلات ساختارى بود.

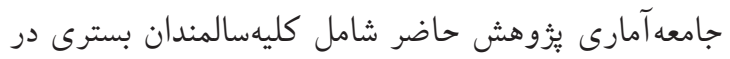

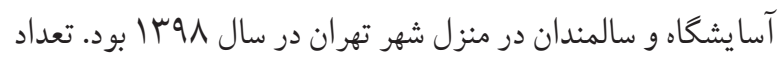

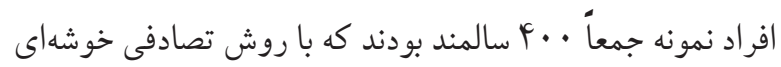
انتخاب شدند. بدينصورت كه از بين مراكز نكهدارى سالمندان ابتدا

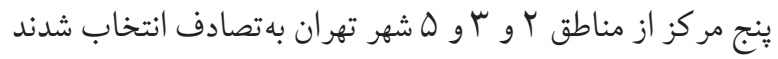

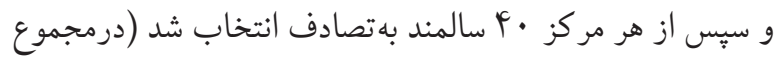

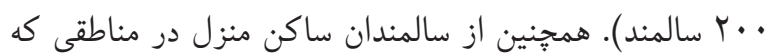

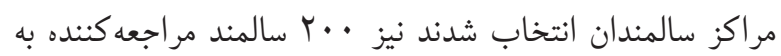
سراى محلات (له سراى محله) انتخاب و يرسشنامهها توسط خود آنها و در حضور ثئوهشكر تكميل شد ( •lf سالمند مراجعه كننده

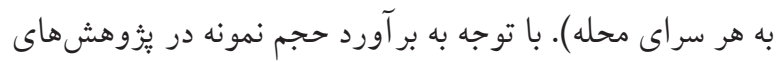

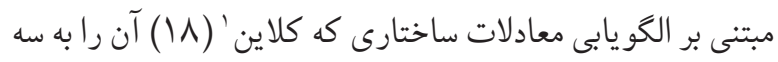
نوع ساده، كمى بيجيده و الكوى بيجيده تقسيم مى كنند و با توجه 
AGFI"

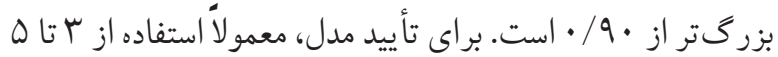
شاخص كافى به نظر مىرسد(1) (1).

يافته ها

نتايج تحليل دادههاى جمعيتشناختى نشان داد

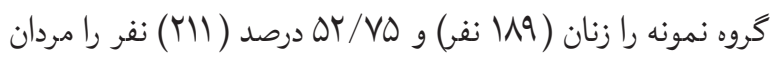

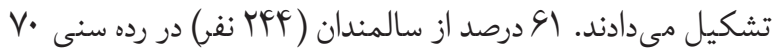

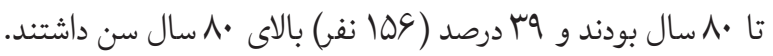

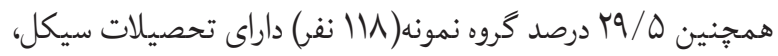

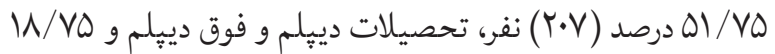
درصد (VD) نفر داراى تحصيلات ليسانس و بالاتر بودند. يافتهاى توصيفى متغيرهاى يُزوهش در جدول ( (1) آورده شده است.

جدول ا: يافتههاى توصيفى خردهمقياسهاى تحقيق

\begin{tabular}{|c|c|c|c|c|}
\hline كشيدكى & كجى & استاندارد انحراف & ميانگين & \\
\hline $.11 .-$ & $\cdot, \vee \wedge-$ & 0,90 & $Y \wedge, \wedge F$ & يذيرش خود \\
\hline $01 \cdot .-$ & $\cdot$ & $\Delta, \Delta \wedge$ & rG, १९ & هدفمندى \\
\hline IrF. & $\cdot, \mathrm{\vee} \Delta-$ & $\Delta, r$. & $r \cdot, v{ }^{q}$ & رشد فردى \\
\hline rs..- & $\cdot, r V-$ & $\Delta, r \mu$ & rV,VF & تسلط محيطى \\
\hline rrs.- & $\cdot, 4 q_{-}$ & $\Delta, r \Lambda$ & $\lceil\wedge, \Upsilon \wedge$ & استقلال \\
\hline GYF.- & • & $\Delta, F \wedge$ & rV,rs & رشد فردى \\
\hline Fr人.- & $\cdot,{ }^{4} \wedge-$ & $r, \Delta$. & $\wedge, \Delta \wedge$ & تفكر عاملى \\
\hline 1.r.- & $\cdot, \mathrm{VS}-$ & $\mu, \mu$. & $9, r \varsigma$ & تفكر مسير \\
\hline $4 \wedge \cdot .-$ & $\cdot, \cdot V$ & r, rᄉ & $\vee, \wedge \vee$ & اضطراب مرى \\
\hline
\end{tabular}

يكى از مفروضههاي مدلسازى معادلات ساختارى نرمال بودن توزيع جندمتغيرى است. براى اين منظور در نرمافزار VerY.

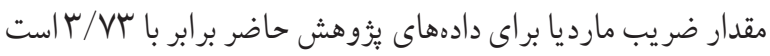
كه نشان مى دهد مفروضه نرمال بودن جِند متغيره برقرار است. در

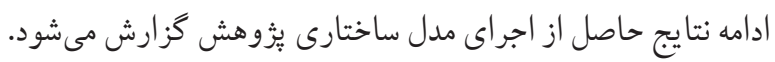

6. Adjusted Goodness of Fit Index

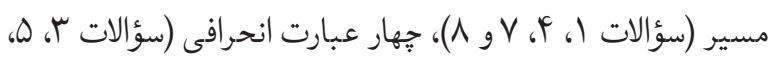
و و (1) است. بنابراين اين برسشنامه دو زيرمقياس عامل و راهبرد را اندازهيرى مى كند. هر ماده با مقياس جهاردرجهاى اندازه گيرى

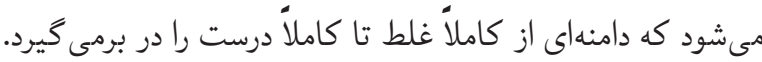

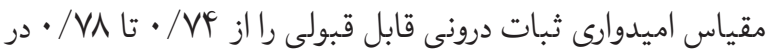

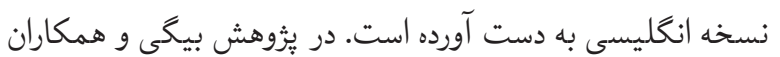

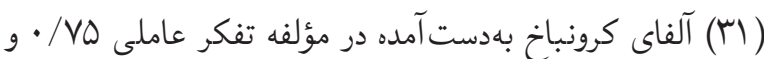
براى مؤلفه تفكر مسير VN/ • بهدست آمده است.

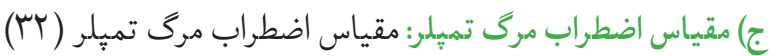
ابزارى براى اندازهيرى اضطراب مربوط به مرى بوده كه بيشترين

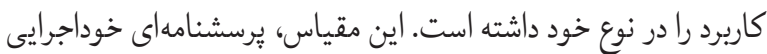

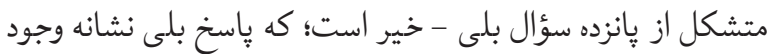

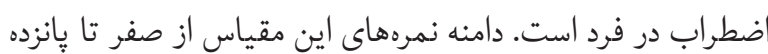

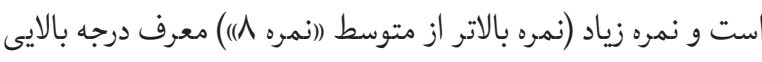
از اضطراب مرگ است. اين ثبرسشنامه توسط رجبى و بحرانى (سب) به فارسى بركردانده شده است. بايايى و روايى برسشنامه اضطراب مرگ نشان مى دهد كه مقياس از اعتبار قابل قبولى بهرهمند است.

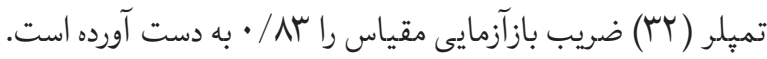

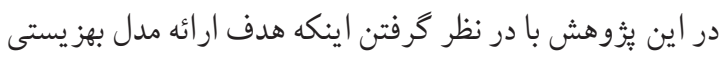

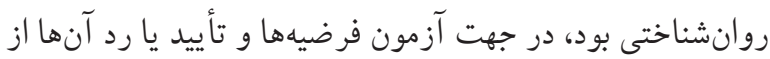
مدلسازى معادلات ساختارى و آزمون ميانجى سوبل استفاده شد. براى انجام تجزيهوتحليل دادههاى يُزوهش از نرمافزارهاى SPSS

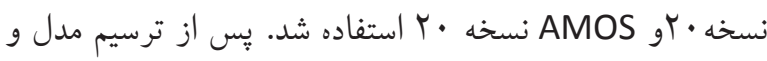
اطمينان اوليه از صحت و معنادارى اطلاعات، مهمترين مبحث،

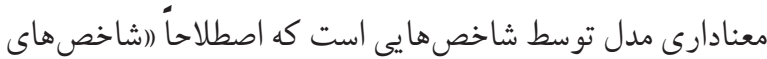

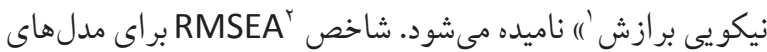

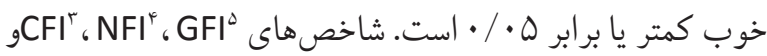

1. Goodness of fit indices

2. Root Mean Square Error Approximation

3. Comparative Fit Index

4. Normed Fit Index

5. Goodness of Fit Index 


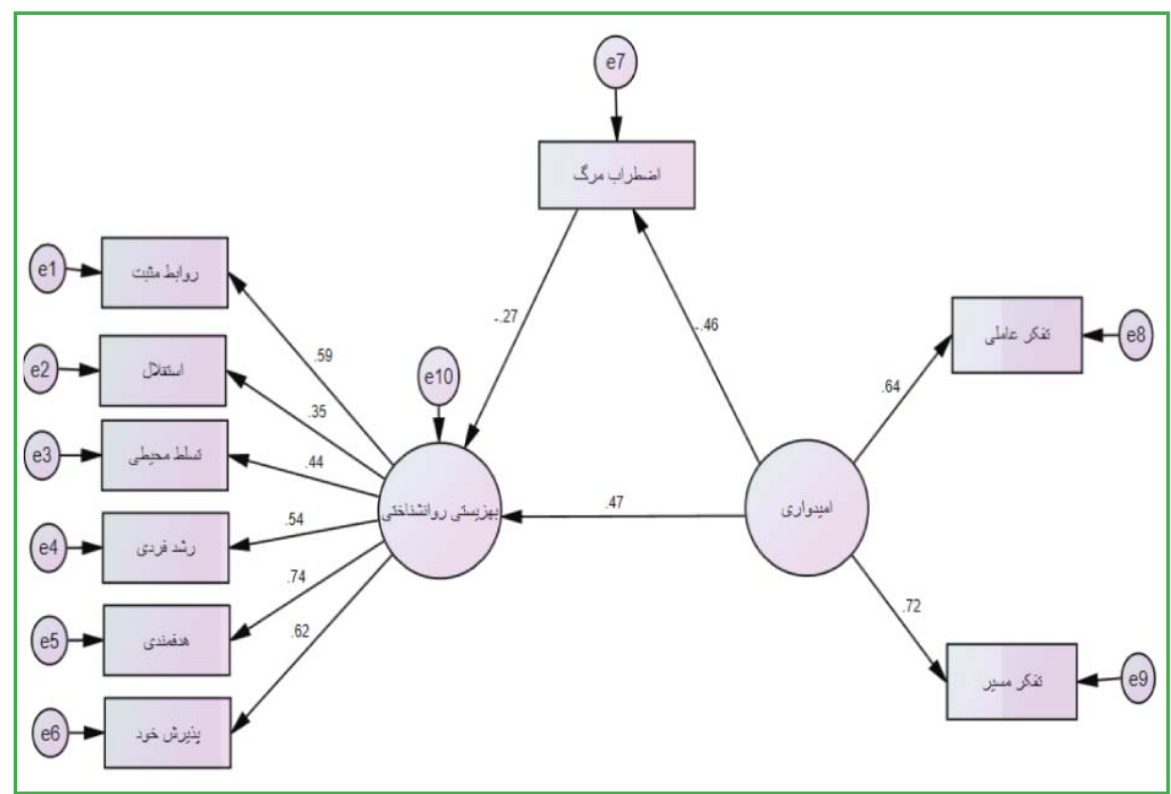

شكل ا: مدل در حالت ضرايب استانداردشده

جدول r: شاخصهاى برازش مدل

بهطور كلى در كار با برنامه آموس هر يك از شاخصهاى

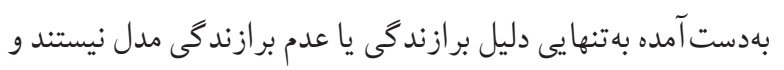

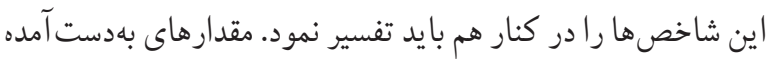
براى اين شاخصها نشان مىدهد كه درمجموع الكو در جهت تبيين و برازش از وضعيت مناسبى برخوردار است. همجنين نتايج تحليل

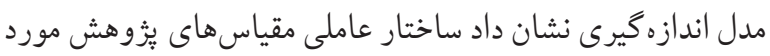

تأييد بود.

\begin{tabular}{|c|c|c|}
\hline \multicolumn{2}{|c|}{ شاخصهاى برازش } & \multirow{2}{*}{ ن ام شاخص } \\
\hline حد مجاز & مقدار & \\
\hline كمتر از & $1 / 19$ & \\
\hline 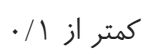 & $\cdot / \cdot r$ & RMSEA ريشه ميانگين خطاى برآورد RM \\
\hline 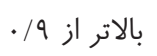 & $\cdot / 9 V$ & CFI برازندگى تعديل يافته \\
\hline بالاتر از 9 ـ. & .194 & برازندگى نُرمشده NFI \\
\hline 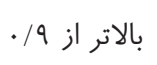 & $\cdot / 91$ & نيكويى برازش GFI \\
\hline 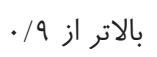 & $\cdot 194$ & نيكويى برازش اصلاحشدهAGFI \\
\hline
\end{tabular}

جدول سا: ضرايب و معنادارى اثرات مستقيم و غير مستقيم بر بهزيستى روانشناختى

\begin{tabular}{|c|c|c|c|c|c|c|}
\hline sig & آماره معنادارى & B م استاندار دشده & ضريب استاندارد & 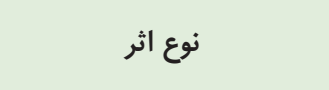 & متغير پِيشبين & متغير ملاك \\
\hline$\cdot / \cdots 1$ & S/MT & $\cdot / F V$ & $\cdot / 4 \wedge$ & مستقيم & 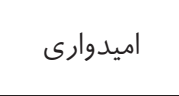 & روانشزيستى \\
\hline$\cdot / \cdot r$ & $r / r q$ & r & $\cdot / 10$ & با ميانجيگرى اضطراب مرى & اميدوارى & روانشزيستى \\
\hline.$/ \cdots 1$ & $-\Delta / \cdot \mathcal{F}$ & $-\cdot / 4 s$ & $-\cdot / \mu$ & مستقيم & اضطراب مرى & روانشزيستى \\
\hline
\end{tabular}


براى زندكى دنيوى و سالهاى باقيمانده از عمر، مىتواند راهى براى اجتناب از فكر كردن به نزديك بودن بايان زندگى مرگ باشد ( • بـ).

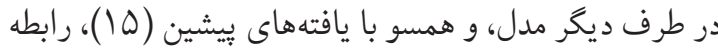
اضطراب مرى با بهزيستى روانشناختى منفى و معنادار است.

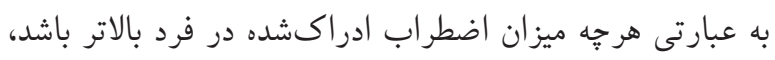
سطح بهزيستى روانشناختى در ايشان كاهش مى يابد. اين نتيجه

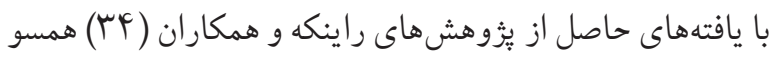

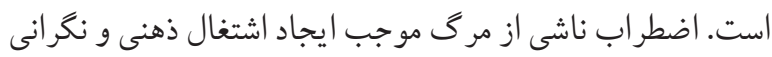
دائمى و مانع احساس تسلط، رشد شخصى و روابط مثبت با ديكران

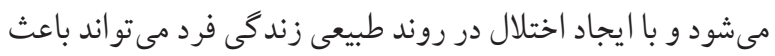

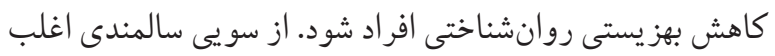

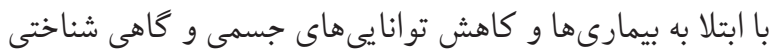

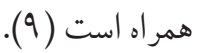
در جارجوب نظر يه ريف (9) يكى از مؤلفهاى كليدى بهز يستى،

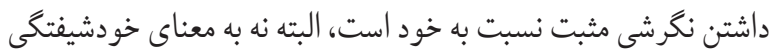

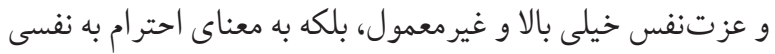

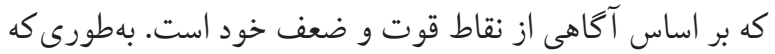

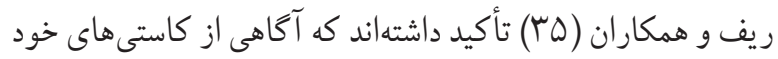
و نيز يذيرش اشتباههاى خو يش، يكى از مشخصههاى بسيار مهم

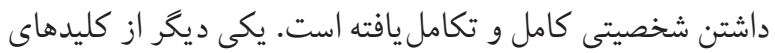
رسيدن به بهز يستى، تحت كنترل داشتن جهان يير امون است؛ يعنى

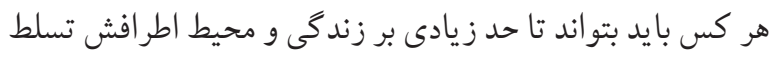

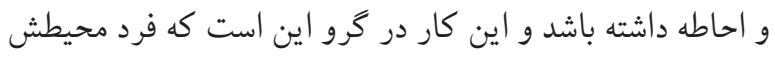

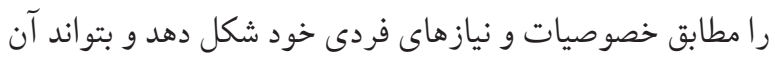
را به همان شكل نكه دارد. جنين تسلط و احاطهاى تنها از تلاش و عملكرد خود فرد و در متن كار، خانواده و زندگى اجتماعى سلى

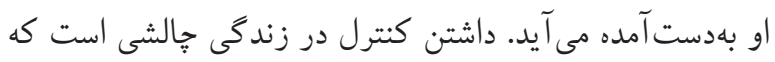

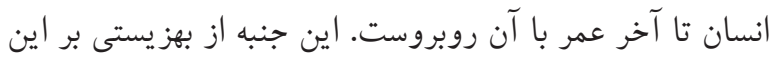

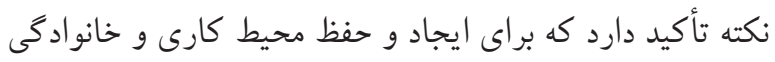
مطلوب هر شخصى، همواره به خودمختارى و نيروى خلاقانه او احتياج است. شرايط اجتماعى -اقتصادى بسيارى از سالمندان، همونان
آنجه از نتايج جدول گ برمى آيد اين است كه عوامل اميدوارى و اضطراب مرى اثر مستقيم بر بهزيستى روانشناختى داشتهاند. همجنين فرضيه مطرح شده در ارتباط با وجود اثر غيرمستقيم اميدوارى لترى

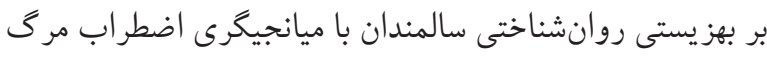

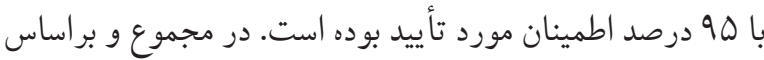

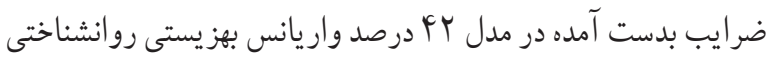

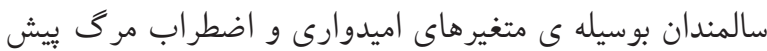

$$
\text { بينى شدهاند. }
$$
يافتهاى يُزوهش حاكى از برازش مناسب مدل مفهومى يُّوهش بود. رابطه مستقيم اضطراب مرگ با بهزيستى روانشناختى و اميد در

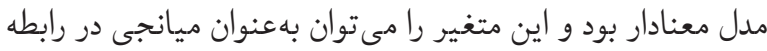

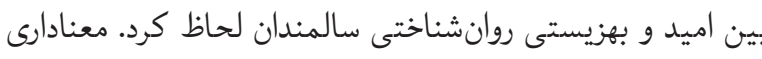

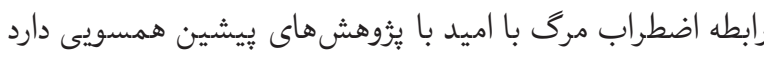
(1). اضطراب و ترس از مرگ در ميان تمام فرهنگها متداول است و گروهها و اديان مختلف به طرق گوناگون با آن برخورد مى كنند؛ بنابراين اضطراب مرى نقش عمدهاى در تجربه درونى انسانها دارد و ذهن آنها را به طرز بى بديلى تسخير مي كند. فرد براى روبهرو

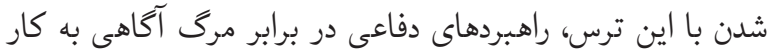

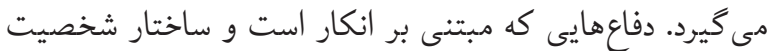

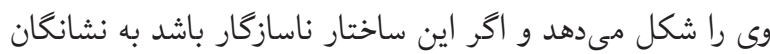

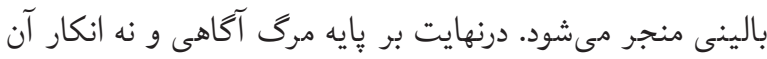

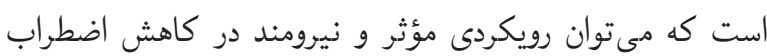
مرگ بنا نهاد (Tr). لذا عوامل و ويثگى هاى متعددى در ارتباط با يديده مرگ وجود دارند كه مى توانند زمينهساز يذيرش اين واقعيت

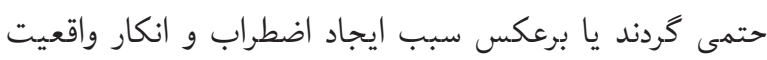

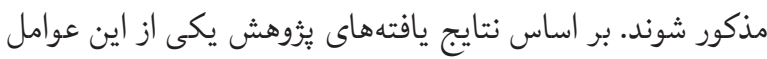

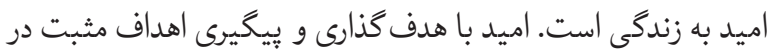
زندكى همراه دانسته شده و گويههاى يرسشنامه اميد اسنايدر كه در

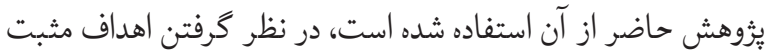


نشان داد كه متغيرهاى سطح فردى يعنى اميد به زندگى و اضطراب مرى با بهز يستى روانشناختى رابطه دارد. اما ميزان واريانس تبيين شده كامل نبود. اين امر نشان مىدهد كه عوامل ديخرى نيز در سطح مختلف مانند سطح خانوادگى و اجتماعى بر اين متغير تأثير مى گذارند كه لزوم شناسايى و بررسى آنها در يزوهش هاى آتى احساس مىشود. همجنين نمونه موردبررسى تحقيق حاضر سالمندان مناطق r r ا ه شهر تهران بودند. بنابراين تعميم يافتها به سالمندان شهرهاى ديخر با محدوديت مواجه است و لازم است تحقيقات در زمينه تعميم يذيرى يافتهها تكر ار كردد.

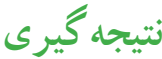

بر اساس نتايج ييشنهاد مىشود كه مراكز نگهدارى سالمندان در برنامهريزى ها و يزوهشهاى مربوط به ارتقاى سلامت روان ازجمله بهزيستى روانشناختى در سالمندان به جگگونكى تأثير اميد به زندكى و اضطراب مرگ، توجه ويثهاى داشته باشند. بهرغم اين كه يديده سالمندى يك موفقيت بهداشتى براى جامعه محسوب مى شود، عدم برنامهريزى مناسب براى ييشگيرى زودهنگام از مشكلات سالمندى، به ايجاد جالشى بزرگ براى جامعه منجر خواهد شد. اولين گام براى برنامهريزى مناسب بهمنظور ارتقاى سلامت، بيشخيرى از بروز و ابتلا به بيمارىهاى مزمن و كاهش شيوع بيمارىهاى خاص در سالمندان، شناسايى وضعيت و عوامل مؤثر بر سلامت روانى و جسمى سالمندان و نيز تعيين سالمندان در معرض آسيب از آسيب يذير شدن آنان

$$
\text { ييشخيرى كرد. }
$$

\section{References}

1. Sori, A, Shabani Moghadam, K, Soury, R. The Effect of physical activity on quality of life in elder women in Kermanshah Province. Applied Research in Sport Management, 2016; 4(4): 75-84. ]Persian[ Retrieved from http://arsmb.journals.pnu.ac.ir/article_2628_en.html

2. World Health Organization. Facts on ageing and the life course. Geneva, Switzerland: WHO; 2014 [cited 2014 Apr 8].

3. Nabavi, S, Alipour, F, Hejazi, A, Rabani, E, Rashedi, V. Relationship between social support and mental health in older adults. Iran J Basic Med Sci., 2014; 57(7): 841-846. ] Persian[ https://dx.doi.org/10.22038/mjms.2014.3756
مديريت اين مسائل را دشوار و آنان را در معرض خطر وابستخى و كاهش خودمختارى قرار مىدهد. اگر سالمندان در جنين شرايطى راهكار مقابلهاى مناسبى براى كنار آمدن با اين روند نداشته باشند و اضطراب مرگ در آنها بالا باشد؛ يعنى با نگاه منفى به ادامه زندگى، مرگ را تنها راه نجات بدانند بهطور مسلم از بهزيستى روانشناختى يايينى برخوردار خواهند بود. در همين راستا نتايج يثزوهش ورعى و همكاران (YV) نشان داد بين اضطر اب مرگ و بهز يستى روانشناختى رابطه معنادارى وجود دارد. با توجه به اين نكته كه اضطراب مرگ، ييشبينى كننده تغييرات مربوط به سلامت عمومى افراد است، بايد به اين نكته اشاره كرد كه تنها رخدادهاى استرسزا نيستند كه سلامت افر اد را تحت تأثير قرار مىدهند، بلكه ارزيابى ها و قضاوتهاى شناختى افراد در مورد آنها عامل تعيين كننده اين تأثير ات است. اين يافته، يافتهاى كاملاً منطقى به نظر مىرسد و با ديد گاههاى نظرى در اين مورد ساز گار است. همانطور كه مشخص است سبك تبيين افراد بر ادراك آنها از اضطر اب تأثير مى گذارد و آنگاهكه اضطر اب كه مورد تأثير سبك تبيين افر اد و اميدوارى آنها هم قرار گرفته است، مى تواند بر سلامت عمومى آنها تأثير گذار باشد و تغييرات مربوط به آن را يِيشبينى كند، بهطورى كه اگر افراد متأثر از سبك تبيين و اميدوارى خود، اضطراب زيادى را درك و تجربه كنند، احتمال به خطر افتادن سلامت آنها افزايش مى يابد.

يزوهش حاضر به ارائه مدل بهزيستى روانشناختى بر اساس اميد به زندگى با ميانجيگرى اضطر اب مرگ سالمندان يرداخت و

4. Hayes N, Joseph S. Big 5 correlates of three measures of subjective well-being. Pers. Individ. Diffe. 2003 Mar 1;34(4):723-7. https://doi.org/10.1016/S01918869(02)00057-0

5. Branstrom, R, Kvillemo, P Moskowitz, J.T A Randomized Study of the Effects of Mindfulness Training on Psychological Well-being aand Symptoms of Stress in Patients Treated for Cancer at 6-month Follow-up. Journal of Behavioral Medicine; 2012: 19(4), 535-542. doi: 10.1007/s12529-011-9192-3.

6. Ryff CD. Happiness is everything, or is it? Explorations on the meaning of psychological well-being. J Pers Soc 
Psychol. 1989 Dec;57(6):1069-1081. https://psycnet.apa. org/doi/10.1037/0022-3514.57.6.1069

7. Seligman, M E P, \& Csikszentmihalyi, M. (2000). Positive psychology: An introduction. Amer. Psychologist, 55(1), 5-14. https://psycnet.apa.org/doi/10.1037/0003066X.55.1.5

8. Stevenson, J.C., Millings, A. \& Emerson, L. Psychological Well-being and Coping: the Predictive Value of Adult Attachment, Dispositional Mindfulness, and Emotion Regulation. Mindfulness 10, 256-271 (2019). https://doi. org/10.1007/s12671-018-0970-8

9. Romero, A., Piña-Watson, B., Stevens, A. K., Schwartz, S. J., Unger, J. B., Zamboanga, B. L., Szapocznik, J., LorenzoBlanco, E., Cano, M. Á., Meca, A., Baezconde-Garbanati, L., Córdova, D., Villamar, J. A., Soto, D. W., Lizzi, K. M., Des Rosiers, S. E., Pattarroyo, M., \& Oshri, A. Disentangling relationships between bicultural stress and mental well-being among Latinx immigrant adolescents; 2020: Journal of Consulting and Clinical Psychology: 88(2): 149159. https://doi.org/10.1037/ccp0000466

10. Kim M, Hyung Kim A, Newman J.I., Ferris G.R, Perrewe $P$. The antecedents and consequences of positive organizational behavior: The role of psychological capital for promoting employee well-being in sport organizations: 2019; 22(1): 108-125.

11. Liao MN, Chen SC, Lin YC, Chen MF, Wang CH, Jane SW. Education and psychological support meet the supportive care needs of Taiwanese women three months after surgery for newly diagnosed breast cancer: A nonrandomised quasi-experimental study. Int J Nurs Stud. 2014 Mar 1;51(3):390-9. https://doi.org/10.1016/j. ijnurstu.2013.07.007

12. Curtis, A J. Health psychology. London: Routledge; 2001

13. Huang G, Wu Y, Zhang G, Zhang P, Gao J. Analysis of the psychological conditions and related factors of breast cancer patients. Chin Ger J Clin Oncol. 2010 Jan 1;9(1):537. https://doi.org/10.1007/s10330-009-0135-2

14. Duggleby, W., Hicks, D., Nekolaichuk, C., Holtslander, L., Williams, A., Chambers, T., Eby, J. Hope, older adults, and chronic illness: a metasynthesis of qualitative research. Journal of advanced nursing; 2012: 68(6): 1211-1223.

15. Tsavena M, Balakrishnan U. The Effect of a Workfare Programme on Psychological Wellbeing in India. Journal The Journal of Development Studies; 2019: 55(12): 25932609. https://doi.org/10.1080/00220388.2018.1502879

16. Long KN.G, Kim, E.S., Chen Y, Wilson M.F., Worthington E., VanderWeele T. The role of Hope in subsequent health and well-being for older adults: An outcome-wide longitudinal approach. Global Epidemiology;.2020: 2: https://doi. org/10.1016/j.gloepi.2020.100018

17. Pourabdol, S, Absasi, M, Pirani, Z, Abbasi, M. The Relationship Between life Expectancy and Psychological
well-Being with Quality of Life in the Elderly. Aging Psychology, 2015; 1(1): 57-65. ]Persian[ Retrieved From https://jap.razi.ac.ir/article_290.html

18. Keshavarz,S. Investigating the relationship between lifestyle and life expectancy with psychological well-being of the elderly in Darab education.2012. Master Thesis. [Persian] Retreived From https://ganj old.irandoc.ac.ir/ articles/590507.

19. Nezamdoost M, Borjali A, Poursharifi H, Keraskian MOJMBARI A, Seirafi MR. The Re lationship between Hope and Sense of Coherence with Psychosocial Wellbeing among Older People: Mediating Role of Attitude toward death. Journal of aging psychology; 2018; 4(3): 179-195. [Persian]. https://jap.razi.ac.ir/article_1013.html

20. Langlois F, Vu TT, Chassé K, Dupuis G, Kergoat MJ, Bherer $L$. Benefits of physical exercise training on cognition and quality of life in frail older adults. J Gerontol B Psychol Sci Soc Sci. 2013 May 1;68(3):400-4. https://doi.org/10.1093/ geronb/gbs069

21. Keng SL, Smoski MJ, Robins CJ. Effects of mindfulness on psychological health: a review of empirical studies. Clin Psychol Rev. 2011;31(6):1041-1056. doi:10.1016/j. cpr.2011.04.006

22. Malliarou M, Sotiriadou K, Serafeim T, Karathanasi K, Moustaka E, Theodosopoulou E, Sarafis P. Greek nurses attitudes towards death. Glob J Health Sci. 2011;3(1):224230. https://doi.org/10.5539/gjhs.v3n1p224

23. Blesky J. The Psychology of Aging. Brooks/Cole Publication Company; 1999.

24. Harmon-Jones E, Simon L, Greenberg J, Pyszczynski T, Solomon S, McGregor H. Terror management theory and self-esteem: Evidence that increased self-esteem reduced mortality salience effects. J Pers Soc Psychol. 1997 Jan;72(1):24. https://doi.org/10.1037//00223514.72.1.24 PMID: 9008372

25. Ghasempour A, Sooreh J, Kand MT. Predicting Death Anxiety on The Basis of Emotion Cognitive Regulation Strategies. Knowledge \& Research in Applied Psychology, 2017; 13(48): 63-70. ]Persian[ Retrieved http://jsr-p. khuisf.ac.ir/article_533827.html

26. Menzies, R.E., Sharpe, L., Dar-Nimrod I. The relationship between death anxiety and severity of mental illnesses. Clinical Psychology, 2020; 58(4): 452-467. https://doi. org/10.1111/bjc.12229

27. varaee $P$, Momeni K, Moradi A. Structural Equation Modeling: A Study on the Effect of Religious Orientation on the Psychological Wellbeing Concerning the Mediating Role of Death Anxiety and Self-compassion in the Male Elderly Living in Kermanshah City in 2017. Salmand: Iranian Journal of Ageing. 2019; 14 (2):162-177. [Persian]. DOI: $10.32598 /$ sija.13.10.360

28. Kline, Rex B. Principles and Practice of Structural Equation 
Modeling. 3rd ed. New York: The Guilford Press; 2011.

29. Kalantarkousheh SM, Navarbafi F. Reliability and Exploratory Factor Analysis of Psychological Well-being in a Persian Sample. Science Series Data Report. 2012 Jan;4(1):16.

30. Snyder CR, Harris C, Anderson JR, Holleran SA, Irving LM, Sigmon ST, Yoshinobu L, Gibb J, Langelle C, Harney P. The will and the ways: development and validation of an individual-differences measure of hope. Journal of personality and social psychology. 1991 Apr;60(4):570585.

31. Beigi, A, Farahani, M, Mohammad-Khani, S, MohammadiFar, M. The Discriminative Role of Quality of Life and Hope in Narcotic Anonymous and Methadone Maintenance Groups. J Clin Psychol. 2011; 3(3): 75-84. ]Persian[ https:// dx.doi.org/10.22075/jcp.2017.2064

32. Templer DI. The construction and validation of a death anxiety scale. J Gen Psychol. 1970 Apr 1;82(2):165-77. https://doi.org/10.1080/00221309.1970.9920634

33. Rajabi, GH, Bohrani M. Item factor analysis of the death anxiety scale. Journal of Psychology, 2002;5(4):331-344. ]Persian[ Retrieved From https://www.sid.ir/En/Journal/ ViewPaper.aspx?ID=39069

34. Reinecke L, Aufenanger S, Beutel ME, Dreier M, Quiring O, Stark B, Wölfling K, Müller KW. Digital stress over the life span: The effects of communication load and internet multitasking on perceived stress and psychological health impairments in a German probability sample. Media Psychol. 2017 Jan 2;20(1):90-115. https://doi.org/10.108 0/15213269.2015.1121832

35. Ryff CD, Love GD, Essex MJ, Singer B. Resilience in adulthood and later life: Defining features and dynamic processes. In Lomrants, J (Ed.). Handbook of Aging and Mental Health: An Integrative Approach. New York: Plenum Press, 1998. p. 69-96 